\title{
Transforming growth factor- $\beta 1$ and activin A generate antiproliferative signaling in thyroid cancer cells
}

\author{
Sílvia Emiko Matsuo, Suzana Garcia Leoni, Alison Colquhoun and Edna Teruko Kimura \\ Department of Cell and Developmental Biology, Institute of Biomedical Sciences, University of São Paulo, Av Prof Lineu Prestes 1524, 05508-000 \\ São Paulo, SP, Brazil \\ (Correspondence should be addressed to E T Kimura; Email: etkimura@usp.br
}

\begin{abstract}
Transforming growth factor-beta 1 (TGF- $\beta 1$ ) and activin A (ActA) induce similar intracellular signaling mediated by the mothers against decapentaplegic homolog (SMAD) proteins. TGF- $\beta 1$ is a potent antimitogenic factor for thyroid follicular cells, while the role of ActA is not clear. In our study, the proliferation of TPC-1, the papillary thyroid carcinoma cell line, was reduced by both recombinant ActA and TGF- $\beta 1$. Due to the concomitant expression of TGF- $\beta 1$ and ActA in thyroid tumors, we investigated the effects of either TGF- $\beta 1$ or ActA gene silencing by RNA interference in TPC-1 cells in order to distinguish the specific participation of each in proliferation and intracellular signaling. An increased proliferation and reduced SMAD2,
\end{abstract}

SMAD3, and SMAD4 mRNA expression were observed in both TGF- $\beta 1$ and ActA knockdown cells. Recombinant TGF- $\beta 1$ and ActA increased the expression of inhibitory $S M A D 7$, whereas they reduced $c-M Y C$. Accordingly, we detected a reduction in SMAD7 expression in knockdown cells while, unexpectedly, $c-M Y C$ was reduced. Our data indicate that both TGF- $\beta 1$ and ActA generate SMADs signaling with each regulating the expression of their target genes, SMAD7 and $c-M Y C$. Furthermore, TGF- $\beta 1$ and ActA have an antiproliferative effect on thyroid papillary carcinoma cell, exerting an important role in the control of thyroid tumorigenesis.

Journal of Endocrinology (2006) 190, 141-150

\section{Introduction}

Transforming growth factor-beta (TGF- $\beta$ ) and activin are structurally related dimeric proteins belonging to the TGF- $\beta$ superfamily, which includes other members such as bone morphogenetic protein, growth and differentiation factor, Müllerian-inhibiting substance, and inhibin (Chang et al. 2002, Miyazawa et al. 2002). While TGF- $\beta$, the first member of the superfamily to be isolated, was initially recognized by its capacity to induce anchorage-independent proliferation of rat fibroblasts (Roberts et al. 1981), activin was originally isolated from the gonads and identified by its ability to stimulate follicle-stimulating hormone secretion from the anterior pituitary (Ling et al. 1986, Vale et al. 1986). Lately, a diversity of biological processes has been attributed to the TGF- $\beta$ superfamily, including control of cell proliferation, differentiation, apoptosis, and development. Much of this knowledge was acquired by studying TGF- $\beta 1$ and activin A (ActA), the most studied isoforms of each family. Despite its original transforming definition, TGF- $\beta$ at present is best known as a potent growth inhibitor for epithelial cells (Roberts \& Sporn 1991). In addition to its role in the reproductive system, activin also induces antiproliferative effects in a range of epithelial cells (Chen et al. 2002). TGF- $\beta$ acts by binding to specific serine/ threonine kinase transmembrane receptors, which induce intracellular signaling by phosphorylation of receptor-regulated mothers against decapentaplegic homolog (R-SMADs), SMAD2 and SMAD3, allowing their interaction with the common-mediator SMAD (co-SMAD), SMAD4, and then this complex moves to the nucleus where it regulates gene transcription (ten Dijke et al. 2000). Although activin binds to its own specific receptors, the same set of SMADs is recruited for its signal transduction. This TGF- $\beta$ /activin signaling is attenuated by SMAD7, an inhibitory SMAD (I-SMAD), that prevents phosphorylation of SMAD2/3 and interferes with the formation of complex SMAD2/3 and SMAD4 (Pangas \& Woodruff 2000, Miyazawa et al. 2002). Although TGF- $\beta$ and activins generate signaling by common intracellular mediators, represented by SMADs $2 / 3$ and 4, they induce specific biological responses (Roberts \& Sporn 1991, Vale et al. 1991). During embryonary development, the distinct role exerted by each member of the superfamily becomes evident by observing mice deficient in TGF- $\beta 1$ or Act $A$. These studies reveal that the majority of the TGF- $\beta 1$ homozygote mutant mice died during embryogenesis and the survivors developed inflammatory infiltrate in multiple organs. Mice deficient in Act $A$, in turn, exhibited craniofacial defects and died during the perinatal period (Chang et al. 2002). These knockout mice models suggest that the lack of one superfamily member is not compensated by another, even though the common pathway 
of SMADs is intact, supporting the specificity and independence of effects generated by each growth factor.

The TGF- $\beta$ inhibitory effect in the proliferation of epithelial cells, such as gastric, pancreatic, mammary and intestinal cells, has been well characterized (Roberts \& Sporn 1991, Siegel \& Massague 2003). On the other hand, the expression of TGF- $\beta 1$ mRNA and protein are increased in tumors derived from epithelial cells when compared with normal cells, suggesting that these tumoral cells became unresponsive to TGF- $\beta 1$ 's growth inhibitory action (Asmis et al. 1996, Siegel \& Massague 2003). In the thyroid, TGF- $\beta$ promotes growth arrest in follicular cells derived from diverse animal species (Morris et al. 1988, Tsushima et al. 1988, Taton et al. 1993, Depoortere et al. 2000). Although activin propagates the same SMAD signaling, its role in the proliferation of thyroid follicular cells is not well clarified (Kotajima et al. 1995, Franzen et al. 1999, Schulte et al. 2000). Thyroid cancer is the most prevalent endocrine malignancy, papillary carcinoma being the most common thyroid carcinoma (DeLellis \& Williams 2004). In previous studies, we observed TGF- $\beta 1$, ActA, and also SMADs expression in thyroid neoplasms (Kimura et al. 1999, Cerutti et al. 2003, Matsuo et al. 2003). The co-expression of TGF- $\beta 1$ and ActA does not permit us to distinguish the individual role of each of these growth factors in the thyroid. To investigate the contribution of each gene in SMADs signal transduction and in cell proliferation, we induced the silencing of the TGF- $\beta 1$ and also of the $A c t A$ gene by RNA interference (RNAi) to analyze the effect of this knockdown upon SMADs gene expression and upon thyroid carcinoma cell proliferation.

\section{Materials and Methods}

\section{Cell culture}

TPC-1, a human papillary thyroid carcinoma cell line (Ishizaka et al. 1990), was kindly provided by Dr J A Fagin (University of Cincinnati College of Medicine, Cincinnati, $\mathrm{OH}, \mathrm{USA}$ ). TPC-1 (referred to as TPC) was maintained in Dulbecco's modified Eagle's medium (DMEM) supplemented with 5\% fetal bovine serum (FBS), $100 \mathrm{U} / \mathrm{ml}$ penicillin, $100 \mu \mathrm{g} / \mathrm{ml}$ streptomycin, and $1 \mu \mathrm{g} / \mathrm{ml}$ amphotericin at $37^{\circ} \mathrm{C}$ in a humidified $5 \% \mathrm{CO}_{2}$ incubator.

\section{Cell proliferation assays}

Cell counting Cells were seeded into six-well plates at a density of $5 \times 10^{4}$ cells/well and cultured for 24,48 , and $72 \mathrm{~h}$, when total confluence was reached. The number of cells was counted in a hemocytometer and the average cell number from quadruplicate measurements was determined.

3-(4,5-dimethylthiazol-2-yl)-2,5-diphenyltetrazolium, bromide (MTT) assay Cells were seeded into 96well plates at a density of $10^{4}$ cells/well. When the cells reached semi-confluence $15 \mathrm{~h}$ after seeding, MTT (Amresco,
Solon, OH, USA) was added to the medium at a concentration of $0 \cdot 125 \mathrm{mg} / \mathrm{ml}$. After $3 \mathrm{~h}$, the medium was removed and the cells were solubilized in $100 \mu \mathrm{l} 0.04 \mathrm{M}$ $\mathrm{HCl}$ in isopropanol and the reaction product was measured by a spectrophotometer at $595 \mathrm{~nm}$.

BrdU labeling and immunocytochemistry Cells were seeded onto chamber slides, and at semi-confluence $(24 \mathrm{~h}$ in culture) were incubated with $10 \mu \mathrm{M}$ bromodeoxyuridine (BrdU; Sigma) for $3 \mathrm{~h}$. The cells were fixed in $4 \%$ paraformaldehyde for $10 \mathrm{~min}$ and incubated with $2 \mathrm{M}$ $\mathrm{HCl}$ for $30 \mathrm{~min}$. The immunocytochemical procedure was performed by an indirect three-stage immunoenzymatic method as described previously (Martins et al. 2002). Briefly, after endogenous alkaline phosphatase was blocked with 15\% glacial acetic acid, cells were incubated with primary antibody mouse monoclonal anti-BrdU overnight. After incubation with biotin-streptavidin-alkaline phosphatase, the reaction was revealed by a mixture of napthol ASMX phosphate, levamisole and fast-red TR salt diluted in veronal acetate buffer $(\mathrm{pH} \quad 8 \cdot 3)$. The cells were counterstained with Gill's hematoxylin. The immunopositivity of the reaction was detected as red color in the nucleus observed by light microscopy. The omission of the primary antibody resulted in a lack of positive staining. For analysis, the percentage of immunopositive cells was determined by counting three different areas in the slide in the total of 900 cells.

\section{$R N A i$}

Construction of small interfering RNA (siRNA) plasmids We used $\mathrm{p}$ Silencer $3 \cdot 1-\mathrm{H} 1$ puro small interfering RNA (siRNA) expression vector (Ambion, Austin, TX, USA), which contains the H1 RNA polymerase III promoter to drive siRNA expression and a puromycin resistant gene to enable antibiotic selection in mammalian cells. To design siRNA, three mRNA target sequences were selected for TGF- $\beta 1$ RNAi (1, GGGCTACCATGCCAACTTC; 2, GACTATCGACATGGAGCTG; 3, GTGGACATCAACGGGTTCA, GenBank accession no. NM_000660) and for ActA RNAi (1, GTTGCTGGATTATAGTGAG; 2, GACGCTGCACTTCGAGATT; 3, GGAGCAGTCGCACAGACCT, GenBank accession no. M13436). For each target sequence, sense and antisense oligonucleotide siRNA were designed following Ambion's guidelines to encode a 19-mer hairpin structure with a loop and $3^{\prime}$ overhanging ends. For annealing of siRNA duplexes, siRNA strands were heated for $3 \mathrm{~min}$ at $95^{\circ} \mathrm{C}$ and then cooled slowly to room temperature. The annealed siRNA insert was ligated into the pSilencer vector according to the manufacturer's instructions. We performed sequencing as described previously (Martins et al. 2002) to confirm insertion of siRNA oligonucleotide into the plasmid. 


\section{siRNA cell lines}

Transfection TPC cells were cultured to approximately 80-90\% confluence. Cells were then transfected with ActA siRNA or TGF- $\beta 1$ siRNA plasmid or with pSilencer negative control (Ambion) using Lipofectamine 2000 (Invitrogen). Stable cell lines $A c t A$ siRNA, TGF- $\beta 1$ siRNA, and negative control siRNA were obtained by using $1 \mu \mathrm{g} / \mathrm{ml}$ puromycin for $2-3$ weeks. For each target sequence of $A c t A$ or $T G F-\beta 1$, one to three stable siRNA cells were generated. Clones of TGF- $\beta 1$ or ActA siRNA that presented at least $60 \%$ inhibition of target genes by quantitative PCR (Fig. 1) were chosen for further analysis. For experimental procedures, third to fifth passages of each clone were used. The morphology of knockdown cells was monitored during culture under an inverted microscope. The ActA siRNA and $T G F-\beta 1$ siRNA cell lines did not exhibit morphological differences when compared with nontransfected TPC observed by inverted light microscopy (Fig. 1C).

\section{Quantitative PCR}

Total RNA was isolated using Trizol (Invitrogen). The first strand of cDNA was generated from $3 \mu \mathrm{g}$ of total RNA as described previously (Matsuo et al. 2003). Primers were designed based on Primer Express Program (Perkin-Elmer Applied Biosystems, Foster City, CA, USA) and are listed in Table 1. Each set of sense and antisense primers was chosen in distinct exons to avoid amplification of genomic DNA. ActA or TGF- $\beta 1$ primers of $600 \mathrm{nM}$ and SMAD2, SMAD3, SMAD4, SMAD7, and ribosomal protein L19 (RPL19) primers of $300 \mathrm{nM}$ were optimized. PCR amplification was performed in duplicate using $50 \mathrm{ng}$ of cDNA, 300 or $600 \mathrm{nM}$ of each primer, and SYBR Green PCR Master Mix (Applied Biosystems, Warrington, UK) in a Gene Amp 5700 Sequence Detection System (Perkin-Elmer Applied Biosystems). PCR carried out without cDNA resulted in no amplification of any target gene. Each PCR reaction was repeated at least twice. The expression of each investigated gene was normalized with housekeeping gene RPL19. Data were calculated using the $2^{-\rho \rho C T}$ method (Livak \& Schmittgen 2001) and are presented as the fold change in gene expression relative to the control sample. For the control sample, $2^{-\rho \rho C T}$ is equal to 1.

The transfected TPC with pSilencer negative control, which encodes a hairpin siRNA whose sequence has no significant homology to known human genes, did not display significantly altered expression of any target gene when compared to nontransfected TPC (data not shown).

\section{Treatment of cells with recombinant human TGF- $\beta 1$ or ActA}

The cell lines were cultured until semi-confluence, when they were treated either with or without $10 \mathrm{ng} / \mathrm{ml}$ TGF- $\beta 1$ (PeproTech, Rocky Hill, NJ, USA) or $70 \mathrm{ng} / \mathrm{ml}$ ActA (PeproTech) and incubated for $3 \mathrm{~h}$ in DMEM 5\% FBS. Total RNA was isolated and subjected to cDNA amplification.

The effect of TGF- $\beta 1$ or ActA addition was also assessed on cell proliferation. For this purpose, cells were seeded into 96-well plates at a density of $10^{4}$ cells/well and treated either with or without $1 \mathrm{ng} / \mathrm{ml} \mathrm{TGF- \beta 1}$ (PeproTech) or $10 \mathrm{ng} / \mathrm{ml}$ ActA (PeproTech) in DMEM 5\% FBS for 24 h. Subsequently, MTT was performed as described earlier.
A

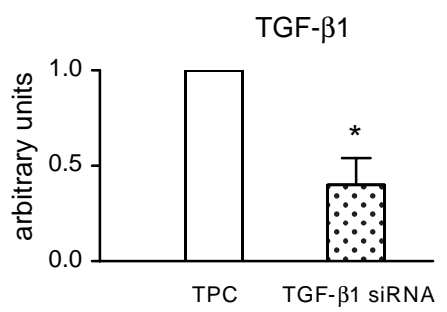

B

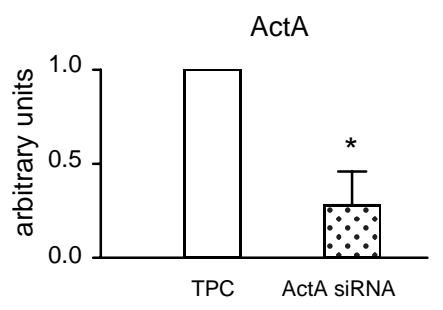

C
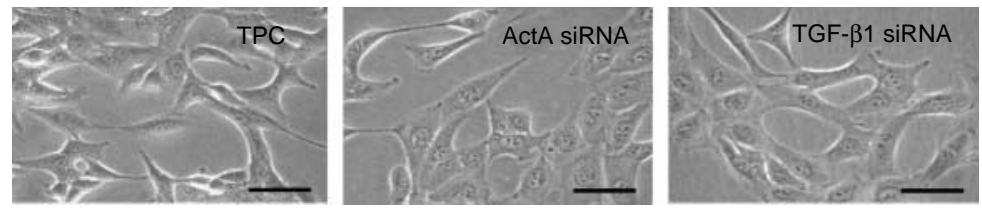

Figure 1 RNAi targeting TGF- $\beta 1$ mRNA and ActA mRNA in the TPC cell line. (A) TGF- $\beta 1$ mRNA expression in TPC transfected with TGF- $\beta 1$ siRNA evaluated by quantitative PCR. (B) Expression of ActA mRNA in TPC transfected with ActA siRNA by quantitative PCR. Columns in graphs $(A)$ and $(B)$ represent mean \pm s.D. of two independent reactions performed in duplicate. (C) Cell morphology in non-transfected TPC, TGF- $\beta 1$ siRNA, and ActA siRNA cell lines observed by inverted light microscopy. Scale bar $=50 \mu \mathrm{m} .{ }^{*} P<0.05$ vs TPC. 
Table 1 Primers used in real-time PCR

Sequence of primers $\left(5^{\prime} \rightarrow 3^{\prime}\right)$

\begin{tabular}{|c|c|}
\hline \multicolumn{2}{|l|}{ Genes } \\
\hline \multirow[t]{2}{*}{ ActA } & Sense GGAGGGCAGAAATGAATGAA \\
\hline & Antisense AATCTCGAAGTGCAGCGTCT \\
\hline \multirow[t]{2}{*}{$T G F-\beta 1$} & Sense CGCGTGCTAATGGTGGAAA \\
\hline & Antisense CGGAGCTCTGATGTGTTGAA \\
\hline \multirow[t]{2}{*}{ SMAD2 } & Sense CCGAAGGCAGACGGTAACA \\
\hline & Antisense CCACTGTAGAGGTCCATTCAGATG \\
\hline \multirow[t]{2}{*}{ SMAD3 } & Sense TCTCCAATGTCAACAGGAATGC \\
\hline & Antisense GAGCCGCACGССТСTTC \\
\hline \multirow[t]{2}{*}{ SMAD4 } & Sense CAGGTGGCTGGTCGGAAA \\
\hline & Antisense AGATCAGGCCACCTCCAGAGA \\
\hline \multirow[t]{2}{*}{ SMAD7 } & Sense CGATGGATTTTCTCAAACCAACT \\
\hline & Antisense CCCTGTTTCAGCGGAGGAA \\
\hline \multirow[t]{2}{*}{$c-M Y C$} & Sense TTCGGGTAGTGGAAAACCAG \\
\hline & Antisense TCCTGTTGGTGAAGCTAACG \\
\hline \multirow[t]{2}{*}{ RPL19 } & Sense TCTCATGGAACACATCCACAA \\
\hline & Antisense TGGTCAGCCAGGAGCTTCTT \\
\hline
\end{tabular}

GenBank Accession no.

M13436

NM_000660

AF027964

NM_005902

U44378

AF015261

X00196

NM_000981

\section{Statistical analysis}

The results of proliferation assays and quantitative PCR are presented as the mean \pm s.D. and were submitted to ANOVA followed by the Bonferroni $t$-test or Student Newman-Keulstest to compare results between groups. Differences were considered significant at $P<0 \cdot 05$.

\section{Results}

We first examined the mRNA expression of TGF- $\beta 1$, ActA, and SMADs in the thyroid cancer cell lines by quantitative PCR. As shown in Fig. 2, we detected expressions of TGF- $\beta 1$, ActA, SMAD2, SMAD3, SMAD4, and SMAD7 in the TPC cell line. In relation to SMADs, the expression of SMAD4 was similar to SMAD7, while SMAD2 presented the lowest expression. The SMAD3 expression was significantly higher than that of SMAD2. However, the ActA mRNA expression was not detected in the NPA papillary thyroid carcinoma cell

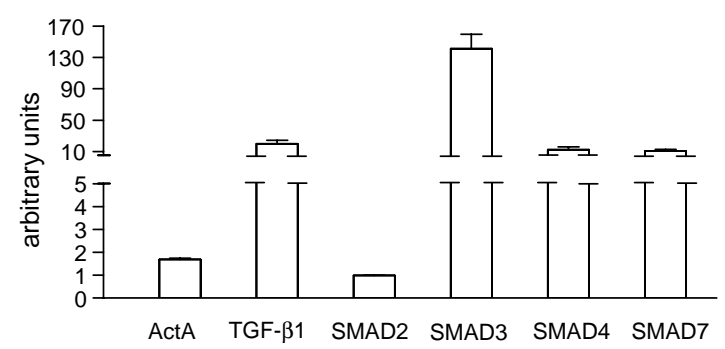

Figure 2 Expression of ActA, TGF- $\beta 1$, SMAD2, SMAD3, SMAD4, and SMAD7 mRNA in TPC cells by quantitative PCR. The gene expression levels were compared with SMAD2 expression in TPC, whose value was determined as $1 \cdot 0$. Columns in the graph represent mean \pm s.D. of two independent reactions performed in duplicate. line and in the ARO anaplastic thyroid carcinoma cell line (data not shown). The fact that TPC cell line expressed TGF- $\beta 1$, ActA, and SMADs led us to choose this cell line as a suitable model for the investigation of the effects of TGF- $\beta 1$ and ActA knockdown on cellular proliferation and on SMADs signaling.

TGF- $\beta 1$ siRNA cell line

Role of $T G F-\beta 1$ in TPC cell proliferation $T G F-\beta 1$ gene silencing resulted in an increase in cell proliferation at 24 $\left(2 \cdot 9 \times 10^{5} \pm 0 \cdot 09\right.$ vs $\left.1.8 \times 10^{5} \pm 0 \cdot 09, P<0 \cdot 05\right)$ and at $48 \mathrm{~h}$ $\left(7 \cdot 5 \times 10^{5} \pm 0 \cdot 25\right.$ vs $\left.6 \cdot 2 \times 10^{5} \pm 0 \cdot 36, \quad P<0 \cdot 05\right)$ during exponential growth by cell counting assay. At $72 \mathrm{~h}$, when the cells reached total confluence, we did not observe any difference in proliferation rate between TGF- $\beta 1$ siRNA cell line $\left(16 \cdot 1 \times 10^{5} \pm 0 \cdot 75\right)$ and $\operatorname{TPC}\left(15 \cdot 9 \times 10^{5} \pm 1 \cdot 1\right)$. Figure $3 \mathrm{~A}$ shows representative results of cell counts.

The MTT assay also showed an increase in cell proliferation rate in TGF- $\beta 1$ siRNA cell line compared with control cells $(0 \cdot 14 \pm 0 \cdot 03$ vs $0 \cdot 08 \pm 0 \cdot 01, P<0 \cdot 05 ;$ Fig. $3 \mathrm{~B})$. The percentage of BrdU labeling was also higher in TGF- $\beta 1$ knockdown cells than TPC (32 vs $15 \%, P<0 \cdot 05$; Fig. 3C).

Role of TGF- $\boldsymbol{\beta} 1$ in SMADs expression To analyze the contribution of TGF- $\beta 1$ to SMADs pathway generation, we verified the gene expression of $S M A D 2, S M A D 3$, and $S M A D 4$ in TGF- $\beta 1$ siRNA cell by real-time PCR. The TGF- $\beta 1$ gene silencing reduced gene expression of SMAD2 by $73 \%, S M A D 3$ by $64 \%$ and $S M A D 4$ by $72 \%$ (Fig. 4 ).

ActA siRNA cell line

Role of $A$ ct $\boldsymbol{A}$ in TPC cell proliferation Like the TGF- $\beta 1$ siRNA cell, a similar result was observed in the $A c t A$ siRNA line by cell counting. The proliferation rate in $A c t A$ siRNA line was 

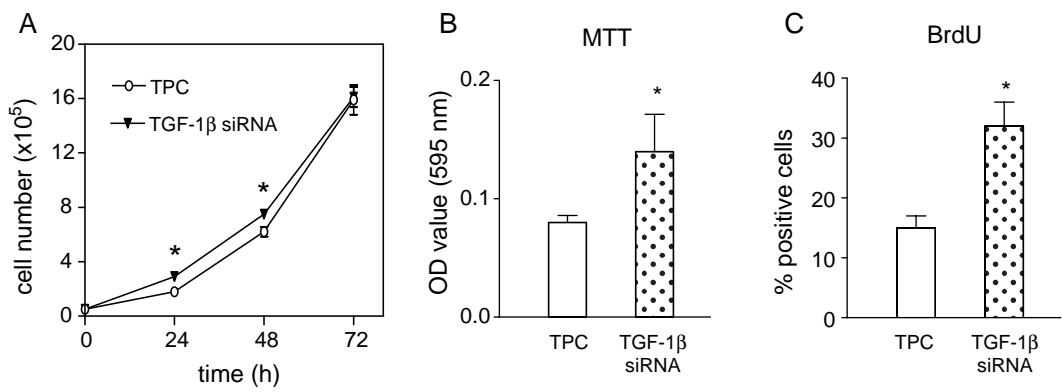

Figure 3 Effect of TGF- $\beta 1$ gene silencing on TPC cell proliferation. (A) Cells were seeded at $5 \times 10^{4}$
cells/well in six-well plates and cell counting was determined at the indicated times. Points represent
mean \pm s.D. of four determinations. Data are representative of two independent experiments. (B) TPC and
$T G F-\beta 1$ knockdown cells were seeded at equal density and cultured until semi-confluence, and then
incubated with MTT for $3 \mathrm{~h}$. Data are presented as the mean \pm s.D. of a single experiment performed in
quadruplicate and are representative of three independent experiments. (C) TPC and TGF- $\beta 1$
knockdown cells were seeded onto glass chamber slides and cultured until semi-confluence, and then
incubated with $10 \mu \mathrm{M}$ BrdU for $3 \mathrm{~h}$. Cells were fixed and then incubated with anti-BrdU antibody and
the immunocytochemistry was performed by the biotin-streptavidin-alkaline phosphatase method. The
percentage of immunopositive cells was obtained by counting three different areas in the slide in the
total of 900 cells. Similar results were obtained in another independent experiment. ${ }^{*} P<0 \cdot 05 \mathrm{vs} \mathrm{TPC.}$

increased at $24\left(2 \cdot 7 \times 10^{5} \pm 0 \cdot 17\right.$ vs $1 \cdot 8 \times 10^{5} \pm 0 \cdot 09, P<$ $0 \cdot 05)$ and at $48 \mathrm{~h}\left(8 \cdot 2 \times 10^{5} \pm 0 \cdot 43\right.$ vs $6 \cdot 2 \times 10^{5} \pm 0 \cdot 36, P<$ $0 \cdot 05)$, but unchanged at $72 \mathrm{~h}\left(16 \cdot 4 \times 10^{5} \pm 1 \cdot 0\right.$ vs $15 \cdot 9 \times 10^{5} \pm 1 \cdot 1$ ), when the cells became confluent (Fig. $5 \mathrm{~A}$ ).

By MTT assay, we also observed an increase in the proliferation rate of $A c t A$ siRNA cells when compared with control TPC $(0 \cdot 12 \pm 0 \cdot 01$ vs $0 \cdot 08 \pm 0 \cdot 01, P<0 \cdot 05$; Fig. 5B). The percentage of labeled cells by BrdU assay was also higher in ActA knockdown cells compared with control (22 vs $15 \%, P<0 \cdot 05$; Fig. 5 C).

Role of ActA in SMADs expression To investigate the involvement of SMADs in the activin pathway, we analyzed SMADs expression in TPC and ActA siRNA cells by quantitative PCR.

As seen in Figure 6, Act $A$ siRNA cells had reduced mRNA expression of $S M A D 2$ by $51 \%, S M A D 3$ by $58 \%$ and $S M A D 4$ by $58 \%$ in comparison to nontransfected TPC.

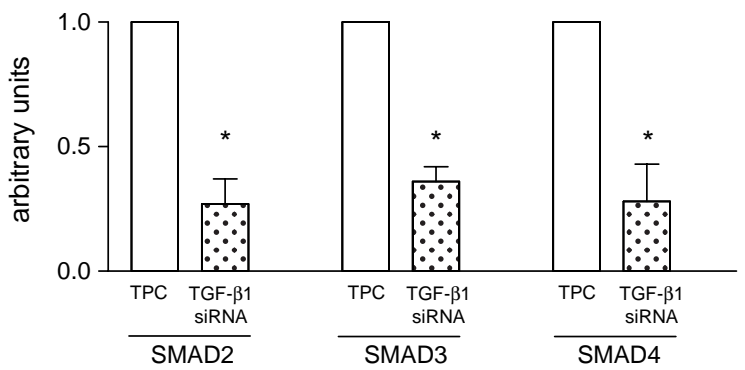

Figure 4 Effect of TGF- $\beta 1$ gene silencing on SMADs expression in TPC cells. The graph shows mRNA expression of SMAD2, SMAD3, and SMAD4 by quantitative PCR. The expression of each gene in non-transfected TPC (control) was determined as value 1. Columns in the graph represent mean \pm s.D. of two independent reactions performed in duplicate. ${ }^{*} P<0 \cdot 05$ vs TPC.
Expression of target genes, SMAD7 and $\mathrm{c}-\mathrm{MYC}$, regulated by TGF- $\beta 1$ and ActA

To examine the effect of TGF- $\beta 1$ and ActA on regulation of target genes by SMAD signaling, we evaluated SMAD7 and c-MYC mRNA expression in TPC and knockdown cells treated either with or without exogenous ActA or TGF- $\beta 1$ by quantitative PCR.

The addition of recombinant TGF- $\beta 1$ or ActA induced an increase in SMAD7 mRNA levels in TPC (Fig. 7A and B). Inhibition of endogenous genes of TGF- $\beta 1$ or $A c t A$ by RNAi resulted in a reduction in SMAD7 expression in TPC cells (Fig. 7C and D).

While the addition of TGF- $\beta 1$ and ActA induced a decrease of c-MYC expression in TPC (Fig. 8A and B), curiously, the silencing of TGF- $\beta 1$ and ActA mRNA in TPC induced a decrease of c-MYC expression (Fig. 8C and D). c-MYC mRNA levels, already low in knockdown cells, were further decreased by TGF- $\beta 1$ or ActA treatment (Fig. 8E and F).

\section{Effects of TGF- $\beta 1$ and ActA on TPC cell and siRNA cell proliferation}

Cell proliferation rate was analyzed by MTT assay in TPC and in knockdown cell lines in the presence or absence of TGF- $\beta 1$ (Fig. 9A) or ActA (Fig. 9B) treatment. Addition of TGF- $\beta 1$ or ActA significantly reduced cell proliferation in TPC. Moreover, upon ActA or TGF- $\beta 1$ treatment, ActA siRNA and also TGF- $\beta 1$ siRNA cells exhibited decreased proliferation rates at similar levels to non-transfected TPC.

\section{Discussion}

We have shown previously that thyroid tumors express TGF$\beta 1$, ActA, and SMAD proteins (Kimura et al. 1999, Cerutti 
A

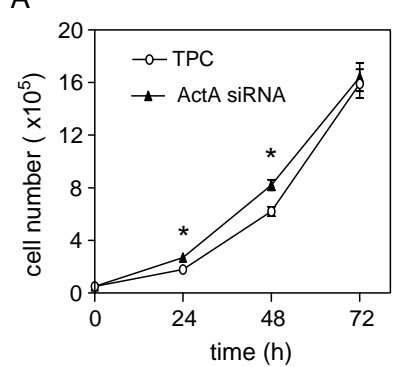

B

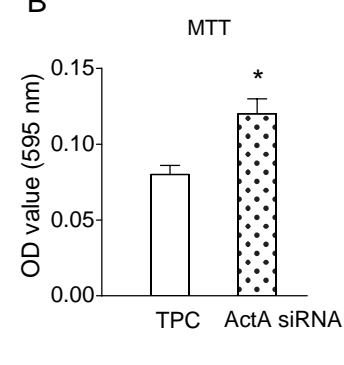

C

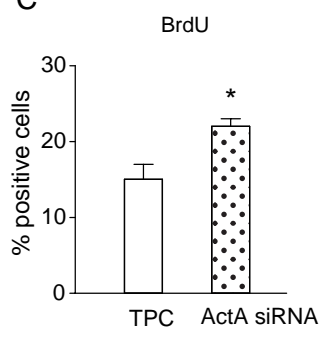

Figure 5 Effect of ActA gene silencing on TPC cell proliferation. (A) Cells were seeded at $5 \times 10^{4}$ cells/well in six-well plates and cell counting was determined at the indicated times. Points represent mean \pm s.D. of four determinations. Data are representative of two independent experiments. (B) TPC and ActA knockdown cells were seeded at equal density into 96-well plates and cultured until semiconfluence, and then incubated with MTT for $3 \mathrm{~h}$. Data are presented as the mean \pm s.D. of a single experiment performed in quadruplicate and are representative of three independent experiments. (C) TPC and ActA knockdown cells were seeded on glass chamber slides and cultured until semiconfluence, and then incubated with $10 \mu \mathrm{M} \mathrm{BrdU}$ for $3 \mathrm{~h}$. Cells were fixed and then incubated with antiBrdU antibody and the immunocytochemistry was performed by the biotin-streptavidin-alkaline phosphatase method. The percentage of immunopositive cells was obtained by counting three different areas in the slide in the total of 900 cells. Similar results were obtained in another independent experiment. ${ }^{*} P<0 \cdot 05$ vs TPC.

et al. 2003, Matsuo et al. 2003). It is well known that TGF- $\beta 1$ and ActA induce intracellular signaling pathways through the same set of SMADs (Pangas \& Woodruff 2000, Miyazawa et al. 2002), but the concomitant expression of both factors raises the question of what is the individual contribution of these proteins in cell proliferation and induction of their mediator SMADs in thyroid cancer. Although the synthetic siRNA induces effective gene silencing, it is highly dependent on the transfection efficiency (Bantounas et al. 2004). In this study, the generation of stable cell lines with long-term gene silencing using siRNA expression vector approach (Sui et al. 2002) allowed us to investigate the effects of continuous TGF- $\beta 1$ or Act $A$ knockdown. The role of TGF- $\beta 1$ as a potent antimitogenic factor is well characterized in rat thyroid follicular cell line as observed in the Fisher rat thyroid cell line (FRTL)-5 cell (Morris et al. 1988, Cirafici et al. 1992, Pang et al. 1992), while the role of ActA in the proliferation of

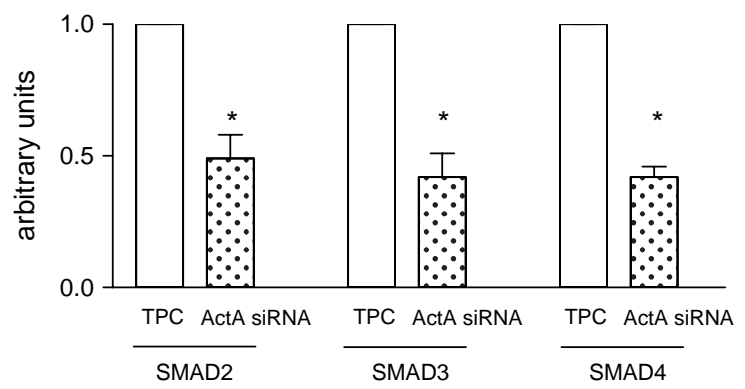

Figure 6 Effect of ActA gene silencing on SMADs expression in TPC cells. The graph shows mRNA expression of SMAD2, SMAD3, and SMAD4 by quantitative PCR. The expression of each gene in nontransfected TPC (control) was determined as value 1. Columns in the graph represent mean \pm s.D. of two independent reactions performed in duplicate. ${ }^{*} P<0 \cdot 05$ vs TPC. follicular cells remains uncertain (Kotajima et al. 1995, Franzen et al. 1999, Schulte et al. 2000). In human thyroid cancer, the effect of TGF- $\beta 1$ or ActA upon cell proliferation is still controversial (Holting et al. 1994, Usa et al. 1994,
A

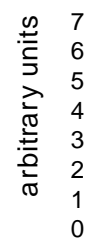

TGF- $\beta 1$

$(10 \mathrm{ng} / \mathrm{ml})$

C

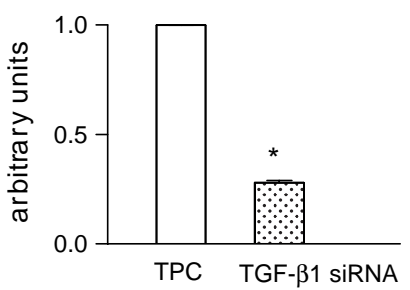

B

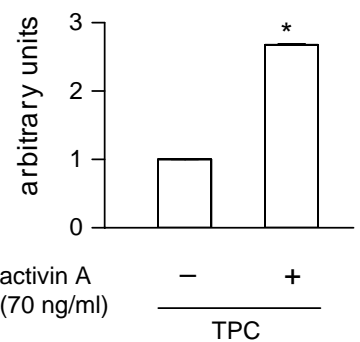

D

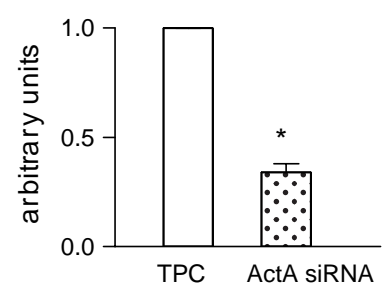

Figure 7 Effect of TGF- $\beta 1$ and ActA on SMAD7 expression. (A and B) Effect of recombinant TGF- $\beta 1$ and ActA on SMAD7 expression in TPC cells by quantitative PCR. TPC cells were incubated either in the absence or in the presence of TGF- $\beta 1$ (A) or ActA (B) in DMEM $5 \%$ FBS for $3 \mathrm{~h}$. Columns in the graph represent mean \pm s. D. of two independent reactions performed in duplicate. ${ }^{*} P<0 \cdot 05$ vs nontreated TPC. (C and D) Expression of SMAD7 in TGF- $\beta 1$ (C) and in $A c t A$ (D) knockdown cell lines by quantitative PCR. Columns in the graph represent mean \pm s.D. of two independent reactions performed in duplicate. ${ }^{*} \bar{P}<0 \cdot 05$ vs TPC. 

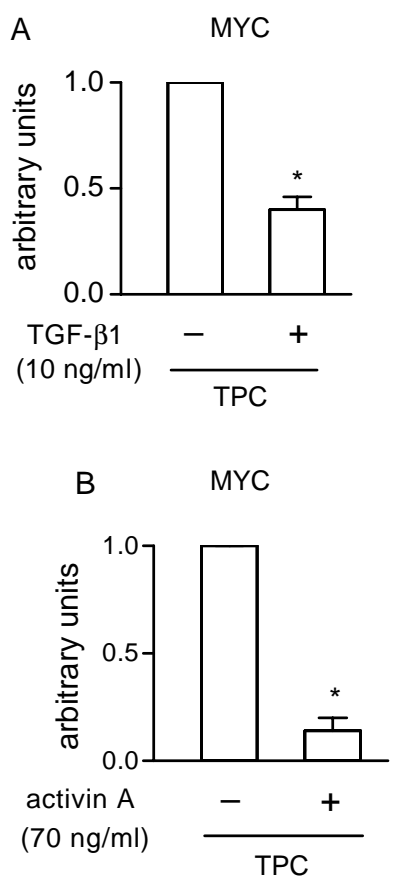

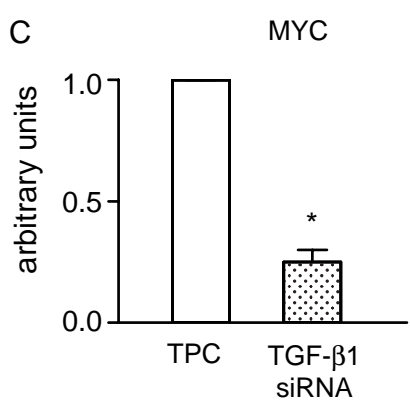

D

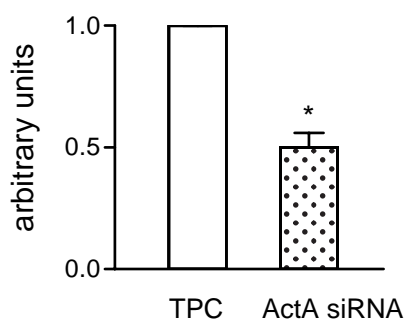

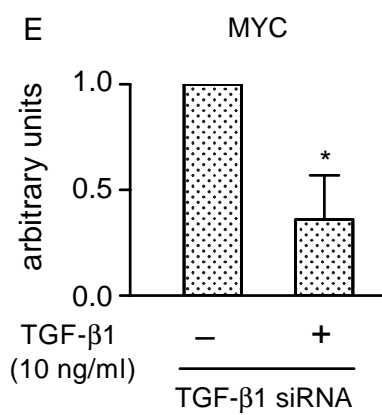

$\mathrm{F}$

MYC

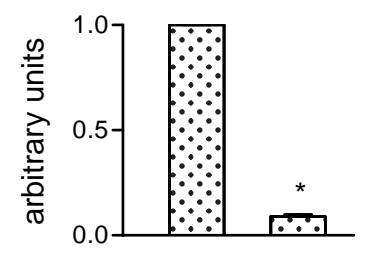

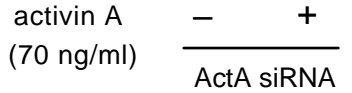

Figure 8 Effect of TGF- $\beta 1$ and ActA on c-MYC expression in TPC. (A and B) Effect of exogenous TGF- $\beta 1$ and ActA proteins on C-MYC expression in TPC cell by quantitative PCR. TPC cells were incubated either in the absence or in the presence of TGF- $\beta 1$ (A) or ActA (B) in DMEM 5\% FBS for $3 \mathrm{~h}$. Columns in the graph represent mean \pm S.D. of two independent reactions performed in duplicate. ${ }^{*} P<0 \cdot 05$ vs nontreated TPC. (C and D) Expression of c-MYC in TGF- $\beta 1$ (C) and in ActA (D) knockdown cell lines by quantitative PCR. Columns in the graph represent mean \pm s.D. of two independent reactions performed in duplicate. ${ }^{*} P<0.05$ vs TPC. (E and F) Effect of exogenous TGF- $\beta 1$ and ActA proteins on C-MYC expression in TPC/siRNA cell by quantitative PCR. TGF- $\beta 1$ (E) and ActA (F) knockdown cell lines were incubated either in the absence or in the presence of TGF- $\beta 1$ (E) or ActA (F) in DMEM 5\% FBS for $3 \mathrm{~h}$. Columns in the graph represent mean \pm s.D. of two independent reactions performed in duplicate. $* P<0 \cdot 05$ vs non-treated siRNA cell.

Ohta et al. 1996, Schulte et al. 2001). Our study indicates that ActA has an antimitogenic role in the TPC cell line, since the addition of recombinant TGF- $\beta 1$ or ActA induced a reduction of cell proliferation in TPC as observed in Figure 9. To further understand the role of endogenous TGF- $\beta 1$ and ActA in thyroid cancer, we analyzed the gene silencing of TGF- $\beta 1$ and the gene silencing of $A c t A$ in TPC cells. The TGF- $\beta 1$ and $A c t A$ knockdown cell lines did not exhibit morphological alterations when compared to nontransfected TPC, as shown in Fig. 1C. Our study showed that Act $A$ gene silencing led to an increase in cell proliferation of TPC, suggesting that endogenous ActA exerts an antiproliferative role. In relation to TGF- $\beta 1$, reducing its gene expression in TPC caused the cells to present a higher proliferation rate, indicating that TGF- $\beta 1$ also exerts antimitogenic effects in this tumor cell. Furthermore, exogenous Act $A$ induced an antiproliferative response in ActA siRNA cells and also reduced proliferation in the TGF- $\beta 1$ siRNA cells (Fig. 9B), compensating the knockdown of TGF- $\beta 1$ in this cell. In addition, these data showed that ActA could induce antiproliferative effects independent of TGF- $\beta 1$. Similarly, the addition of TGF- $\beta 1$ compensated the lack of ActA in ActA siRNA cells and restored the antimitogenic response in the TGF- $\beta 1$ siRNA cell line (Fig. 9A).

The TGF- $\beta 1$ pathway is well known as a tumor suppressor pathway, since TGF- $\beta 1$ is a potent growth inhibitor of most cell types. Inactivation of TGF- $\beta 1$ signaling components, TGF- $\beta$ receptors, SMAD2, SMAD3, or SMAD4, has been found in a variety of cancer cells and loss of these components is associated with escape from TGF- $\beta$ responsiveness (Derynck $e t$ al. 2001, Wolfraim et al. 2004). Our study showed that TPC expresses SMADs mRNA and that RNAi targeting TGF- $\beta 1$ mRNA and ActA mRNA inhibited gene expression of stimulatory SMADs, SMAD2, SMAD3, and SMAD4, thereby suggesting that both TGF- $\beta 1$ and ActA modulate the expression of their mediators and generate signaling that acts cooperatively in thyroid cancer. Although SMAD2 and SMAD3 share a high percentage of homology and both are stimulated by the complex TGF- $\beta$ /receptor or activin/ receptor, many in vitro studies have shown the differential participation of SMAD2 and SMAD3 in transducing the signal generated by TGF- $\beta$ /activin in specific cell types (Kretschmer et al. 2003, Suszko et al. 2005). In SMAD knockout mice, this 
A

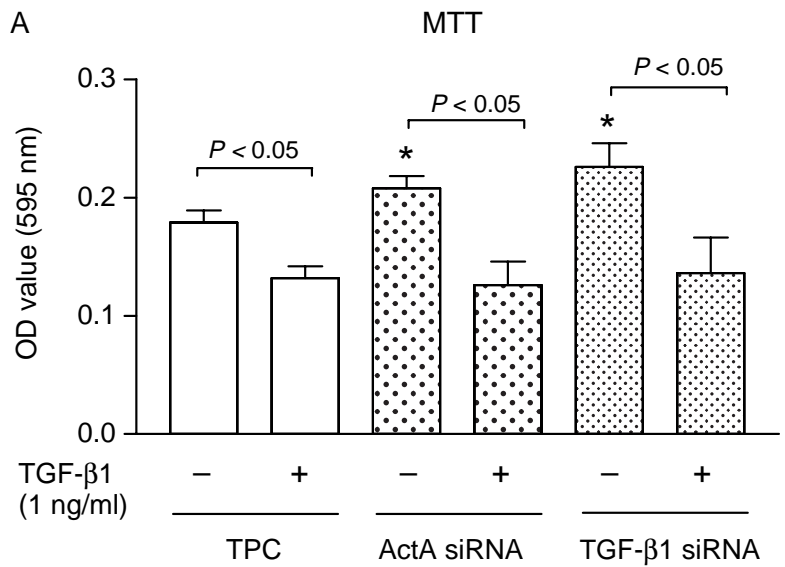

B

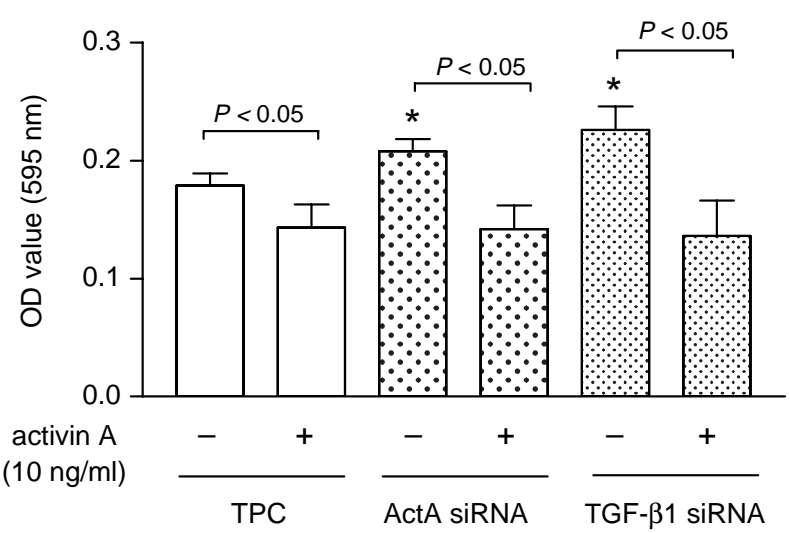

Figure 9 Effect of TGF- $\beta 1$ and ActA on TPC, ActA, and TGF- $\beta 1$ knockdown cell proliferation. TPC and knockdown cells were plated at equal density and incubated either in the absence or in the presence of TGF- $\beta 1$ (A) or ActA (B) in DMEM 5\% FBS for $24 \mathrm{~h}$. Subsequently, cell proliferation rate was measured by MTT assay. Data are presented as the mean \pm s.D. of a single experiment performed in hexaplicate. ${ }^{*} P<0 \cdot 05$ vs TPC.

differential role of each stimulatory SMAD is evident by observation that gene inactivation of either SMAD2 or SMAD3 produces distinct phenotypes (Chang et al. 2002). In our study, although we detected differential expression of SMAD3 and SMAD2 mRNA in TPC cell (Fig. 2), gene expression of either SMAD2 or SMAD3 was reduced in knockdown cells, suggesting an involvement of both $\mathrm{R}-\mathrm{SMADs}$ in thyroid cancer.

TGF- $\beta$ promotes cell growth arrest by induction of cyclin-dependent kinase (CDK) inhibitors p15 and p21 and inhibition of CDK2, CDK4, and CDK6, thereby preventing hyperphosphorylation of $\mathrm{pRB}$ and downregulating $c-M Y C$ (Warner et al. 1999). Since TGF- $\beta$ and activin act through the same SMADs, most of the known mechanisms involved in growth inhibition have been attributed to TGF- $\beta$ action, while the antimitogenic mechanism induced by activin is poorly understood.
Similar to the previous report (Lin \& Ying 1999), we observed a reduced expression of CDK inhibitor p16 in Act $A$ siRNA cells using a membrane array assay, while $\mathrm{p} 21$ expression remained unchanged. Moreover, we did not detect p15 expression even in non-transfected TPC cells by the same approach (data not shown).

SMADs mediate several TGF- $\beta$ and activin functions by modulating the transcription of target genes (Miyazawa et al. 2002 ). To analyze the integrity of TGF- $\beta$ /SMAD and activin/SMAD signaling in the TPC cell line, we examined the expression of two target genes that are known to be regulated by these pathways: $S M A D 7$, whose transcription is stimulated (Afrakhte et al. 1998), and c-MYC, whose transcription is suppressed by TGF- $\beta$ and activin (Miyamoto et al. 1990, Usa et al. 1994). In contrast to stimulatory SMADs (SMAD2, SMAD3, and SMAD4), SMAD7 is a SMAD that inhibits TGF- $\beta$ /activin signaling. Since transcription of $S M A D 7$ is induced by TGF- $\beta /$ SMAD and also by activin/ SMAD pathways, inhibitory SMAD may represent an autoregulatory negative feedback mechanism in TGF- $\beta$ superfamily signal transduction (Pangas \& Woodruff 2000, ten Dijke et al. 2000, Miyazawa et al. 2002). In our study, the addition of TGF- $\beta 1$ and ActA induced an increase of $S M A D 7$ expression, while the knockdown of either TGF$\beta 1$ or Act $A$ genes in turn resulted in decrease of SMAD7 mRNA levels, indicating that $\mathrm{SMAD} 7$ is tightly regulated by TGF- $\beta 1$ and ActA in TPC cell. $c-M Y C$, in turn, is closely implicated in cell proliferation and is one of the most wellknown proto-oncogenes, whose activation is associated with several human tumors (Dang 1999). The c-MYC downregulation mediated by the SMAD signaling pathway confers cell growth arrest in response to TGF- $\beta 1$ and activin (Miyamoto et al. 1990, Warner et al. 1999). In thyroid cancer, the inhibition of $c-M Y C$ induces a decrease in cell proliferation (Usa et al. 1994, Cerutti et al. 1996). When we analyzed the gene expression of $c-M Y C$ in TPC treated with TGF- $\beta 1$ or ActA, we observed a decrease in $c-M Y C$ gene expression (Fig. 8A and B). Despite increased proliferation rates induced by TGF- $\beta 1$ or Act $A$ siRNA, we curiously observed that $c-M Y C$ expression was reduced in both TGF$\beta 1$ and $A c t A$ knockdown cells (Fig. 8C and D). However, the addition of recombinant TGF- $\beta 1$ in TGF- $\beta 1$ siRNA cells and recombinant ActA in ActA siRNA cells led to a reduction of $c-M Y C$ expression (Fig. 8E and F). Although these results are contradictory in normal thyroid follicular cells, the suppression of $c-M Y C$ is not observed in response to TGF- $\beta 1$, even though these cells are responsive to the antimitogenic effect of TGF- $\beta 1$ (Carneiro et al. 1998, Depoortere et al. 2000). On the basis of these data, we would suggest that proliferation in TPC is not mediated by an increase in c-MYC levels. However, these findings remain to be further investigated, since c-MYC not only acts upon cell-cycle progression, but is also involved in several other cellular processes, including apoptosis (Dang 1999).

The loss of responsiveness to TGF- $\beta 1$ and the antiproliferative effects of ActA have been identified in several cancers 
and implicated in tumoral progression (Derynck et al. 2001, Risbridger et al. 2001). Our data showed that the papillary thyroid carcinoma cell line, TPC-1, is still sensitive to the antiproliferative response generated distinctly by TGF- $\beta 1$ and ActA, possibly mediated through a functional SMADs pathway. The presence of this antiproliferative pathway is important to limit the unrestrained cell proliferation induced by mitogenic stimuli in thyroid cancer.

\section{Funding}

This study was supported by research grant from the São Paulo State Research Foundation (FAPESP) and Brazilian Research Council (CNPq) and by a fellowship grant FAPESP 01/08044-0 to S E M. E T K is a CNPq-funded investigator. The authors declare that there is no conflict of interest that would prejudice the impartiality of this scientific work.

\section{References}

Afrakhte M, Moren A, Jossan S, Itoh S, Sampath K, Westermark B, Heldin CH, Heldin NE \& ten Dijke P 1998 Induction of inhibitory Smad6 and Smad7 mRNA by TGF-beta family members. Biochemical and Biophysical Research Communications 249 505-511.

Asmis LM, Kaempf J, Von Gruenigen C, Kimura ET, Wagner HE \& Studer H 1996 Acquired and naturally occurring resistance of thyroid follicular cells to the growth inhibitory action of transforming growth factor-beta 1 (TGFbeta 1). Journal of Endocrinology 149 485-496.

Bantounas I, Phylactou LA \& Uney JB 2004 RNA interference and the use of small interfering RNA to study gene function in mammalian systems. Journal of Molecular Endocrinology 33 545-557.

Carneiro C, Alvarez CV, Zalvide J, Vidal A \& Dominguez F 1998 TGF-beta1 actions on FRTL-5 cells provide a model for the physiological regulation of thyroid growth. Oncogene 16 1455-1465.

Cerutti J, Trapasso F, Battaglia C, Zhang L, Martelli ML, Visconti R, Berlingieri MT, Fagin JA, Santoro M \& Fusco A 1996 Block of c-myc expression by antisense oligonucleotides inhibits proliferation of human thyroid carcinoma cell lines. Clinical Cancer Research 2 119-126.

Cerutti JM, Ebina KN, Matsuo SE, Martins L, Maciel RM \& Kimura ET 2003 Expression of Smad4 and Smad7 in human thyroid follicular carcinoma cell lines. Journal of Endocrinological Investigation 26 516-521.

Chang H, Brown CW \& Matzuk MM 2002 Genetic analysis of the mammalian transforming growth factor-beta superfamily. Endocrine Reviews 23 787-823.

Chen YG, Lui HM, Lin SL, Lee JM \& Ying SY 2002 Regulation of cell proliferation, apoptosis, and carcinogenesis by activin. Experimental Biology Medicine (Maywood) 227 75-87.

Cirafici AM, Pepe S, Mincione G, Esposito D \& Colletta G 1992 TGF beta inhibits rat thyroid cell proliferation without alterations in the expression of TSH-induced cell cycle-related genes. Biochemical and Biophysical Research Communications 187 225-233.

Dang CV 1999 c-Myc target genes involved in cell growth, apoptosis, and metabolism. Molecular and Cellular Biology 19 1-11.

DeLellis RA \& Williams ED 2004 Thyroid and parathyroid tumours: introduction. In World Health Organization. Classification of Tumours. Pathology and Genetics of Tumours of Endocrine Organs, pp 51-56. Eds RA DeLellis, RV Lloyd, PU Heitz \& C Eng. Lyon, France: IARC Press.

Depoortere F, Pirson I, Bartek J, Dumont JE \& Roger PP 2000 Transforming growth factor beta(1) selectively inhibits the cyclic AMP-dependent proliferation of primary thyroid epithelial cells by preventing the association of cyclin D3-cdk4 with nuclear p27(kip1). Molecular Biology of the Cell 11 1061-1076.

Derynck R, Akhurst RJ \& Balmain A 2001 TGF-beta signaling in tumor suppression and cancer progression. Nature Genetics 29 117-129.

Franzen A, Piek E, Westermark B, ten Dijke P \& Heldin NE 1999 Expression of transforming growth factor-beta1, activin $\mathrm{A}$, and their receptors in thyroid follicle cells: negative regulation of thyrocyte growth and function. Endocrinology 140 4300-4310.

Holting T, Zielke A, Siperstein AE, Clark OH \& Duh QY 1994 Transforming growth factor-beta 1 is a negative regulator for differentiated thyroid cancer: studies of growth, migration, invasion, and adhesion of cultured follicular and papillary thyroid cancer cell lines. Journal of Clinical Endocrinology and Metabolism 79 806-813.

Ishizaka Y, Ushijima T, Sugimura T \& Nagao M 1990 cDNA cloning and characterization of ret activated in a human papillary thyroid carcinoma cell line. Biochemical and Biophysical Research Communications $168402-408$.

Kimura ET, Kopp P, Zbaeren J, Asmis LM, Ruchti C, Maciel RM \& Studer H 1999 Expression of transforming growth factor beta1, beta2, and beta3 in multinodular goiters and differentiated thyroid carcinomas: a comparative study. Thyroid 9 119-125.

Kotajima A, Miyamoto Y, Tsuruo M, Kosaka M \& Saito S 1995 Effects of activin $\mathrm{A}$ on deoxyribonucleic acid synthesis, iodine metabolism, and cyclic adenosine monophosphate accumulation in porcine thyroid cells. Endocrinology 136 1214-1218.

Kretschmer A, Moepert K, Dames S, Sternberger M, Kaufmann J \& Klippel A 2003 Differential regulation of TGF-beta signaling through Smad2, Smad3 and Smad4. Oncogene 22 6748-6763.

Lin S \& Ying SY 1999 Differentially expressed genes in activin-induced apoptotic LNCaP cells. Biochemical and Biophysical Research Communications 257 187-192

Ling N, Ying SY, Ueno N, Shimasaki S, Esch F, Hotta M \& Guillemin R 1986 Pituitary FSH is released by a heterodimer of the beta-subunits from the two forms of inhibin. Nature 321 779-782.

Livak KJ \& Schmittgen TD 2001 Analysis of relative gene expression data using real-time quantitative PCR and the 2(-delta delta $\mathrm{C}(\mathrm{T})$ ) method. Methods 25 402-408.

Martins L, Matsuo SE, Ebina KN, Kulcsar MA, Friguglietti CU \& Kimura ET 2002 Galectin-3 messenger ribonucleic acid and protein are expressed in benign thyroid tumors. Journal of Clinical Endocrinology and Metabolism 87 4806-4810.

Matsuo SE, Ebina KN, Kulcsar MA, Friguglietti CU \& Kimura ET 2003 Activin betaB expression in rat experimental goiter and human thyroid tumors. Thyroid 13 239-247.

Miyamoto Y, Kosaka M, Eto Y, Shibai H \& Saito S 1990 Effect of erythroid differentiation factor on erythroid differentiation and proliferation of K-562 cells. Biochemical and Biophysical Research Communications 168 1149-1156.

Miyazawa K, Shinozaki M, Hara T, Furuya T \& Miyazono K 2002 Two major Smad pathways in TGF-beta superfamily signalling. Genes to Cells 7 1191-1204.

Morris JC 3rd, Ranganathan G, Hay ID, Nelson RE \& Jiang NS 1988 The effects of transforming growth factor-beta on growth and differentiation of the continuous rat thyroid follicular cell line, FRTL-5. Endocrinology $1231385-1394$.

Ohta K, Pang XP, Berg L \& Hershman JM 1996 Antitumor actions of cytokines on new human papillary thyroid carcinoma cell lines. Journal of Clinical Endocrinology and Metabolism 81 2607-2612.

Pang XP, Park M \& Hershman JM 1992 Transforming growth factor-beta blocks protein kinase-A-mediated iodide transport and protein kinase-C-mediated DNA synthesis in FRTL-5 rat thyroid cells. Endocrinology 131 45-50.

Pangas SA \& Woodruff TK 2000 Activin signal transduction pathways. Trends in Endocrinology and Metabolism 11 309-314.

Risbridger GP, Schmitt JF \& Robertson DM 2001 Activins and inhibins in endocrine and other tumors. Endocrine Reviews 22 836-858. 
Roberts AB \& Sporn MB 1991 The transforming growth factor- $\beta$ s. In Peptide Growth Factors and Their Receptors I, pp 418-472. Eds MB Sporn \& AB Roberts. New York, NY, USA: Springer-Verlag.

Roberts AB, Anzano MA, Lamb LC, Smith JM \& Sporn MB 1981 New class of transforming growth factors potentiated by epidermal growth factor: isolation from non-neoplastic tissues. PNAS 78 5339-5343.

Schulte KM, Jonas C, Krebs R \& Roher HD 2000 Activin A and activin receptors in the human thyroid: a link to the female predominance of goiter? Hormone and Metabolic Research 32 390-400.

Schulte KM, Jonas C, Krebs R \& Roher HD 2001 Activin A and activin receptors in thyroid cancer. Thyroid 11 3-14.

Siegel PM \& Massague J 2003 Cytostatic and apoptotic actions of TGF-beta in homeostasis and cancer. Nature Reviews Cancer 3 807-821.

Sui G, Soohoo C, Affar el B, Gay F, Shi Y \& Forrester WC 2002 A DNA vector-based RNAi technology to suppress gene expression in mammalian cells. PNAS $995515-5520$

Suszko MI, Balkin DM, Chen Y \& Woodruff TK 2005 Smad3 mediates activin-induced transcription of follicle-stimulating hormone beta-subunit gene. Molecular Endocrinology 19 1849-1858.

Taton M, Lamy F, Roger PP \& Dumont JE 1993 General inhibition by transforming growth factor beta 1 of thyrotropin and cAMP responses in human thyroid cells in primary culture. Molecular and Cellular Endocrinology 95 13-21.

ten Dijke P, Miyazono K \& Heldin CH 2000 Signaling inputs converge on nuclear effectors in TGF-beta signaling. Trends in Biochemical Sciences 25 64-70.

Tsushima T, Arai M, Saji M, Ohba Y, Murakami H, Ohmura E, Sato K \& Shizume K 1988 Effects of transforming growth factor-beta on deoxyribonucleic acid synthesis and iodine metabolism in porcine thyroid cells in culture. Endocrinology 123 1187-1194.
Usa T, Tsukazaki T, Namba H, Ohtsuru A, Kimura H, Villadolid MC, Nagataki S \& Yamashita S 1994 Correlation between suppression of c-myc and antiproliferative effect of transforming growth factor-beta 1 in thyroid carcinoma cell growth. Endocrinology 135 1378-1384.

Vale W, Rivier J, Vaughan J, McClintock R, Corrigan A, Woo W, Karr D \& Spiess J 1986 Purification and characterization of an FSH releasing protein from porcine ovarian follicular fluid. Nature 321 776-779.

Vale W, Hsueh A, Rivier C \& Yu J 1991 The inhibin/activin family of hormones and growth factors. In Peptide Growth Factors and Their Receptors II, pp 210-248. Eds MB Sporn \& AB Roberts. New York, NY, USA: Springer-Verlag.

Warner BJ, Blain SW, Seoane J \& Massague J 1999 Myc downregulation by transforming growth factor beta required for activation of the p15(Ink4b) G(1) arrest pathway. Molecular and Cellular Biology 19 5913-5922.

Wolfraim LA, Fernandez TM, Mamura M, Fuller WL, Kumar R, Cole DE, Byfield S, Felici A, Flanders KC, Walz TM et al. 2004 Loss of Smad3 in acute T-cell lymphoblastic leukemia. The New England Journal of Medicine $351552-559$.

Received in final form 3 March 2006

Accepted 28 March 2006

Made available online as an Accepted Preprint 21 April 2006 